\title{
Authentic Leaders May Increase Employee Innovation: The Mediation Effect of Psychological Capital
}

\section{Nur Maulany Din El Fath ${ }^{\mathrm{a}}$ and Tulus Budi Sulistyo Radikun ${ }^{\mathrm{b}}$}

${ }^{a}$ Faculty of Psychology, Universitas Indonesia, Depok, Indonesia; ${ }^{b}$ Department of Industrial and Organizational Psychology, Faculty of Psychology, Universitas Indonesia, Depok, Indonesia

*Corresponding author:

Tulus Budi Sulistyo Radikun

Department of Industrial and Organizational Psychology

Faculty of Psychology, Universitas Indonesia

Depok, Jawa Barat, Indonesia

Email address: tulus@ui.ac.id 


\title{
Authentic Leaders May Increase Employee Innovation: The Mediation Effect of Psychological Capital
}

\begin{abstract}
Innovation plays the main role in organizational survival in the globalized era of technology and information exchange. Innovation can only be achieved when employees are able to engage in innovative work behavior. In addition, the workplace leader is known to occupy an important role in the formation of innovative employee behavior. Hence, this study tends to see the role of authentic leadership as a predictor for innovative work behavior by using PsyCap as a mediator in analysis of it. There were 115 participants who filled in self-report questionnaires which were distributed online for this study. Mediation analysis using PROCESS macros showed that when psychological capital is fully mediated $(\mathrm{B}=0.071, \mathrm{SE}=0.036,95 \% \mathrm{CI}[0.009,0.150])$ there exists a relationship between authentic leadership and innovative work behavior.
\end{abstract}

Keywords: authentic leadership, innovative work behavior, psychological capital

\section{Introduction}

The urgency for organizations to be innovative is increasing alongside the development of technology and I.T. more generally. The World Economic Forum (2018) reports that, according to U.S. Bureau of Labor Statistics, workers' productivity across industries has increased by $47 \%$ over the past 20 years due to the implementation of technology and innovation. As industries embark upon the fourth industrial revolution, the adoption of technology will lead organizations to focus on innovation in order to develop productivity, worker proseperity and safety, quality, and creating impactful business value (World Economic Forum, 2018). By innovating, companies can identify various risks and opportunities in order to remain competitive (Waite, $\&$ Alina, 2014). Innovation is known to have benefits such as long-term organizational survival and increased effectiveness of the organization (Janssen, Onne, de Vliert, and West, 2004). Moreover, (Baer, Markus, \& Frese, 2003) also mention that innovation could potentially increase market share and profits, thereby allowing an organization may avoid bankruptcy. This argument is also in line with the findings of Stamler \& Philip (2007), that companies with higher innovation will be more financially sustainable in the long-term.

The emergence of innovation in organizations depends on the human capital within them, and employee behavior is seen as a key factor in the process of building innovative values (De Jong, Jeroen, \& Den Hartog, 2007; Janssen, 2000; Youdth et.al, 1996). Therefore, Agarwal and Uspana (2014) emphasize the need for organizations to proactively and intensively stimulate employees' innovative work behavior in order to increase the emergence of innovation at the organizational level. Innovative work behavior is an activity that begins with the creation of new ideas and adaptation of previous ideas, which is then followed by the search for organizational backing so that employees may then implement the idea (Scott, \& Bruce, 1994). 
Many researchers have revealed the antecedents of innovative work behavior. Scott and Bruce (1994) found that workplace group relations (e.g., team-member exchange), and individual attributes (e.g., systematic problem-solving styles) are important antecedents of innovative work behavior. Moreover, certain leadership actions also serve as predictors of innovative behavior, such as allowing collaboration and creativity to emerge in the workplace, and placing trust in subordinate employees thereby creating a sense of job autonomy while undertaking their work (Scott, \& Bruce, 1994). West and Farr (2018) also proposed the factors that contribute to innovative work behavior, such as job factors (e.g., job autonomy, job demand); group factors (e.g., cohesiveness); working relationship (e.g., leader's support for innovation, work involvement, feedback); and, organization factors (e.g., norms, participative culture).

As mentioned previously, a leader's role in shaping innovative behavior is usually quite influential. Some research findings have also confirmed that leaders are essential in ensuring the improvement of innovative workplace behavior (Saeed, et al., 2018; Afsar \& Mariam, 2018). Leaders are a great influencer of innovative behavior because they have the absolute authority to decide whether the ideas discussed are to be executed or implemented. Furthermore, they can encourage innovation initiatives with employees and build communication strategies for supporting the innovation processes within the company (Harborne, \& Axel, 2003). In addition, De Jong, Jeroen, and Den Hartog (2007) found various remarkable behavioral aspects of leadership that influence subordinate's innovativeness. For example, acting as a role-model by demonstrating innovative behavior, in turn stimulates the subordinates to do likewise. Leaders can also trigger idea generation among the employees; stimulate knowledge diffusion in the workplace; provide a sense of direction in order to achieve goals and realize the organization's vision; collate feedback and consult with the work teams; and, most importantly, they provide support for innovation processes which require a trial-error process and tolerance of failure. These aspects not only trigger generation of ideas, but also facilitate the idea implementation process itself (De Jong, Jeroen, \& Den Hartog, 2007). As Abdolmaleki et al.'s (2013) study of 278 employees and 61 managers in the private sector in Iran demonstrates, leaders positively and meaningfully affect employee's innovative workplace behavior. Therefore, leaders need to apply proper behavioral standards and leadership styles to ensure that innovation in organizations can be achieved.

Many studies of leadership have found the significant influence which effective leadership styles can have on innovativeness e.g., authentic leadership (Schuckert, et al., 2018), transformational leadership (Elrehail, et al., 2018), servant leadership (Yoshida, et al., 2014), and transactional leadership (Agbim, 2013). However, in this study, authentic leadership (AL) was established as the predictor variable since it is considered as a style that incorporates elements of various leadership theories, such as transformational leadership, servant leadership, charismatic leadership, and spiritual leadership, as well as other positive leadership styles (Avolio, Bruce \& Gardner, 2005). AL is a 'root construct' of leadership theories, which means it established the basis of other forms positive leadership, and it is therefore assumed to promote more genuine and sustainable performance (Avolio, Bruce \& Gardner, 2005). Nevertheless, not many studies have compared the differences which leadership styles can have on innovative 
behavior. So, far, only Schuckert et al. have managed to reveal that AL has a stronger effect on predicting innovative behavior than transformational leadership (Schuckert, et al., 2018).

AL is one of the most important types of leadership that is a subject of concern for practitioners (Banks, et al., 2016), and it has also been found to have an influence on innovative behavior. A study of 388 employees in China should that employees who perceived their leaders as authentic are likely to: bring innovative solutions to their daily activities; to have higher confidence to offer ideas which can be taken to implementation; and, easily to deal with problems and opportunities at work (Zhou, et al., 2014). This is in line with the findings of Schuckert et al., which revealed that AL can significantly enhance innovative behavior of frontline employees when serving customers (Schuckert, et al., 2018).

Authentic leaders will increase innovative behavior by demonstrating transparency in their relationships with employees, which in turn builds trust and belief that the work context is safer for them (Müceldili, Turan, \& Erdil, 2013). This creates a perception of psychological safety for employees (Rego, et al., 2014), which will help them to freely engage in producing innovative work with comfortable accommodation of interpersonal risk taking (Rego, et al., 2014). Following this logic, we assumed that to better understand the psychological processes of AL on influencing innovative work behavior we needed to use a mediation variable.

Some researchers have done mediation studies on the relationship between AL and innovative behavior, yet it remains limited in scope. A researcher with more than two hundred samples in Portugal found that hope acted as mediator between AL and creativity (Rego, et al., 2014), while creativity is the first stage of innovation, that only reserve idea generation and idea promotion (Baer, 2012). Müceldili, Turan, and Erdil (2013) suggest that authentic leaders may foster innovation via building confidence and optimism, promoting employees' resilience, and therefore creating hope among the subordinates. At the same time, optimism, resilience and hope are widely known as the key dimensions of psychological capital (Avolio, Bruce \& Gardner, 2005).

PsyCap (psychological capital), are positive psychological resources consisting of hope, selfefficacy, resilience, and optimism (Avolio, Bruce \& Gardner, 2005). The positive relationship between PsyCap and innovative behavior is supported by previous studies. A study conducted in Egypt found that each of the dimensions of PsyCap is increase innovative work behavior (Sameer, 2018). Employees will face constant pressure and demands within the organization in order to innovate, which in turn leads to high levels of work stress (Abbas \& Usman, 2015). Additionally, employees must face challenges and stressors in the workplace, take risky actions and exert extraordinary effort to be able to innovate and to be creative (Zhou, et al., 2014) while simultaneously performing their everyday working duties. When employees face such challenges, PsyCap takes a role as a positive psychological resource that can help reduce work stress. Adequate personal PsyCap resources therefore allow individuals to accomplish innovative work processes (Maher, Mahmoud, and Hefny, 2017). 
Unfortunately, there is a limited amount of study which directly places/examines PsyCap as a mediator in the relationship between $\mathrm{AL}$ and innovative work behavior. However, it is necessary to understand the psychological process that lies behind the development of employees' innovativeness, especially the constructs which act as mediators. By understanding the process (as based on the research findings here) practitioners will, hopefully, be able to provide suitable intervention which supports the process of developing innovative work behavior in the workplace. The goal of this study is to reveal the mediation role of psychological capital on the relationship between AL and innovative work behavior. This research is expected to provide theoretical contributions and confirm the relationship between AL, PsyCap, and innovative work behavior.

\section{Theoretical Background}

\section{Authentic Leadership}

AL is a quality of leaders characterized by: having self-awareness with positive self-concept and emotional intelligence; having integrity and learning goal orientation due to their unbiased processing; building relational authenticity by openness and truthfulness in relationships with others; and, showing consistent authentic behavior that reflects one's true self (Ilies, Morgeson, \& Nahrgang, 2005). Authentic leaders dare to show their true self, in order that others are able to perceive them as someone who acts and thinks authentically, is full of hope and optimistic, with a high moral character, and who could thus react and behave in accordance with a given context (Avolio, Walumbwa, \& Weber, 2009). In this study, the definition of AL refers to patterns of leader behavior which promote and draw upon both positive psychological capital and a positive ethical context. These qualities stimulate greater self-awareness, an internalized moral perspective, relational transparency, and balanced processing of information in work interactions with followers, all of which results in positive self-development (Walumbwa, et al., 2007).

AL consists of four constituent dimensions: self-awareness; relational transparency; balanced processing; and, an internalized moral perspective (Walumbwa, et al., 2007). Self-awareness refers to one's appropriate understanding of the strengths, capacities, shortcomings, and sensemaking process. Relational transparency is showing one's true self in order to build a connection based on trust in others. Balanced processing is a leader's ability to objectively analyze all relevant data in the decision-making process. Finally, an internalized moral perspective is an integrated and internalized form of individual self-regulation (Walumbwa, et al., 2007).

\section{Psychological Capital}

Psychological capital (PsyCap) is an individual's positive psychological state, characterized by: (1) having self-efficacy that promotes confidence to deploy suitable efforts required to succeed at challenging tasks; (2) forming a positive attribution (optimism) to succeed and accomplish targets for now and in the future; (3) showing hope as indicated by perseverance toward goals in order to succeed; and, (4) having resilience and being able to bounce back and exhibit sustained effort when having problems and facing adversity yet managing to attain success (Luthans, et al., 2007). Individuals with high PsyCap will show more confidence thereby 
boosting: their ability to be more creative; try new approaches and ways of doing work with energy and perseverance; and, using cognitive resources, positive attitudes and hope in order to succeed (Gonçalves, \& Brandão, 2017). Psychological capital is a positive organizational behavior that functions as a psychological resource which helps an individual effectively generate novelty and reduce work stress (Abbas \& Usman, 2015).

\section{Innovative Work Behavior}

Innovative work behavior is a set of activities that begins with idea generation-by creating a new one or adapting available ideas — and is then followed by making efforts to find support to others to actualize the idea ("idea promotion"), in order to achieve the goal to present new things (idea realization) (Scout, \& Bruce, 1994). In idea generation, employees need to recognize problems, to be able to get new ideas or solutions, and after that, these ideas and solutions will be promoted to significant stakeholders (e.g., colleague, leader, teams, etc.). By innovating, employees could reinvent and/or apply new and useful ideas, processes, products, or procedures of worth to the organization (Zhou, 2014).

\section{The Relationship between AL and Innovative Work Behavior with PsyCap as Mediator}

Considering that leaders play an important role in idea formation, goal planning, and the formation of an innovative work culture, a study with more than 500 samples at 113 different Spanish work teams found that authentic leaders develop organizational climates that support innovative ideas. Thus, employees are able to: understand the mission clearly; to participate actively in innovative work; to seek new ways to improve work performance; and, to share their ideas and perspectives (Edú-Valsania, Moriano, \& Molero, 2016). AL was also found to be positively correlated with innovation of work groups mediated by the member's perception of support for innovation (Černe, Jaklič, \& Škerlavaj, 2013).

According to Zhou et al. (2014) the concept of AL in influencing others is well explained via social learning theory. Social learning theory emphasize that individuals are able to learn and improve through observing interactions in social settings, in other words, individuals' future actions are guided by previously observed behaviors and experiences (Munyaka, et al., 2017). Following this, the role of an authentic leader is significant for the learning environment for subordinates in the workplace, especially for innovative work process. Authentic leaders represent the motif of "leading by example" because they demonstrate these positive qualities by their actions and words (Avolio, \& Gardner, 2005). The observation of actions and the behavior of an authentic leader will provide subordinates with the basis for learning ideal behavior, and thus they can process only relevant information and qualities which they need. Thus, when an authentic leader is able to provide an environment and show behavior in the work processes that triggers innovation, it is likely that subordinates will reveal their own innovative work behavior also.

In this sense, AL promotes a supportive working climate within which there is a desire to innovate. Furthermore, a positive psychological condition such as authenticity (i.e., being true to the self, showing genuine emotions, and managing internal values and beliefs) passes onto employees, allowing them to feel more positive overall. In line with previous findings which 
should that the more employees perceived their leader as authentic, the more likely they are to experience positive emotions, i.e., bravery and optimism (Zhou, 2014). The highly positive context the authentic leaders built may leads to an individual's positive psychological condition, which widely known as psychological capital (Müceldili, Turan, \& Erdil, 2013; Černe, Jaklič, and Škerlavaj, 2013; Elrehail, et al., 2018).

The relationship between AL and PsyCap has been found in the most recently undertaken studies. AL increases employees PsyCap because employees obtained perceived support from their leaders (Munyaka, et al., 2017). The self-confidence of authentic leaders is also found to affect the psychological climate such that it provokes hope and optimism among the employees (Munyaka, et al., 2017). A study with more than 800 samples in New Zealand found AL has significantly increases PsyCap (Woolley, Caza, \& Levy, 2011). AL elevates employees' performance by supporting leader-member exchange process and thereby increasing employees PsyCap (Wang, et al., 2014).

As we use PsyCap as the mediator, there are many previous studies which show that PsyCap is effective at mediating innovative work behavior. As a positive psychological condition, PsyCap has the potential to provide a set of psychological resources that helpful to the emergence of innovative behaviors related to work and the reduction of work (Abbas \& Raja, 2015; Ziyae, Mobaraki, \& Saeediyoun, 2105). PsyCap is found to fully mediate the relationship between AL and creativity (Rego, et al., 2012), which is well known as the first step toward exhibiting innovative behavior (Waite, 2014). Previous research also reveals that personal PsyCap acts as an additional resource in the innovation process, where PsyCap has a greater influence on employees' innovative behavior more than, say, the climate itself (Hsu, \& Chen, 2017). In other words, PsyCap is likely to induce a positive state which will stimulate innovative behavior (Luthans, Youssef, \& Rawski, 2011). For example, when an individual is facing problems when trying to be innovative with tasks, PsyCap, may allow him/her to resiliently bounce back and thereby build the underlying optimism necessary to successfully engage in problem-solving.

The role of PsyCap as the mediator in the relationship between AL and innovative work behavior is well explained by the broad-and-build theory. According to broad-and-build theory, when individuals are exposed to positive emotions, it will create within them the long-term effects required for successful individual performance. Specifically, individuals will be able to discover new ideas, take creative action, and build social bonds (Fredrickson, 2004). The exposure of this loosely structured kind of positivity will consequently release internal individual personal resources, i.e., physical, intellectual, social, and other psychological resources (Fredrickson, 2004). Thus, given the dimensions of AL which may generate more positive achievements among employees (by shaping employees' trust and hope and support resiliency) it will thereby inflict higher emotional security and unconventional work idea proposals from employees and naturally establish innovation in the workplace (Zhou, 2014; Rego, et.al., 2014). By understanding these explanations, we assume that employees are surrounded by the supportive climate which authentic leaders have built, and that they are also being exposed to positive emotions manifested by the leaders. This will increasingly affect their PsyCap as an internal resource, thereby creating innovative work behavior. 
Hypothesis: PsyCap mediates the relationship between AL and innovative work behavior.

\section{Methodology}

\section{Sample and Demographic}

The participants of this study are from the Indonesian workforce, with an age criterion between 19 and 64 years, and with the minimum education requirements of high school level attainment. This is to ensure that participants can understand the questionnaire instructions correctly. Respondents were selected using a convenience sampling method. The questionnaires are distributed online using kwiksurvey.com. Hence, the final $\mathrm{N}=115$. Participants consisted of men $(51 \%)$ and women $(49 \%)$; the age range is $19-37$ years $(\mathrm{M}=26.15 \mathrm{SD}=25.68)$, and with $1-$ 137 months job tenure $(\mathrm{M}=24.5 \mathrm{SD}=24.56)$. Participants are working for the government $(21.7 \%)$, in the private sector $(71.3 \%)$, in non-profit organizations $(3.5 \%)$, as well as a few others.

\section{Instruments}

\section{Authentic Leadership}

Employees are asked to assess the authenticity of their direct supervisor's leadership style, using 16 items on the Authentic Leadership Inventory (ALI) (Neider, \& Schriesheim, 2011). This has been translated into Bahasa Indonesian by Meliala (2014). ALI measures AL dimensions consisting of balanced processing; and internalized moral perspective; relational transparency; and, self-awareness. All dimensions together will indicate how authentic the leader is perceived to be by participants. Response range from 1 = "Strongly Disagree," to 6 = "Strongly Agree." An item example is "My supervisor carefully listens to alternative perspectives before reaching a conclusion" $(\alpha=.90)$.

\section{Psychological Capital}

Employee's psychological capital is measured by 12 short versions of the Indonesian version of the Psychological Capital Questionnaire as adapted from a scale developed by Luthans et al. (2016) and retrieved officially from www.mindgarden.com. The responses ranged from $1=$ "Strongly Disagree," to 6 = "Strongly Agree." The item example is "I always look on the bright side of things regarding my job" $(\alpha=0.87)$.

\section{Innovative Work Behavior}

Employee's innovative work behavior is measured via an adaptation of the Innovative Work Behavior Questionnaire (IWBQ) questionnaire produced by Janssen et.al (2004), and which has been translated into Indonesian by Ahmad (2016). IWBQ's three dimensions of innovative work behavior (idea generation, idea promotion, and idea realization) are examined as nine items that produce a single overall score, using a scale of 1 = "Never," to $6=$ "Very Often." An item example is "I get approval for innovative ideas that I delivered" $(\alpha=0.91)$.

\section{Results}

Hypothesis testing carried out by mediation analysis follows Hayes's procedure (2013) and is calculated using the PROCESS Macro version 3.0 (accessed via www.processmacro.org) in 
SPSS 21 version, and using model number 4. PROCESS Macro allows testing of the relationship of direct effects and indirect effects (mediation) (Hayes, 2013).

This study found a significant relationship between AL and innovation, AL and psychological capital, and psychological capital and innovative work behavior. When psychological capital is incorporated into the model, there is a decrease in the strength of the relationships that were initially significant, to become insignificant with regard to AL and innovation (see Table 2).

The mediation analysis shows PsyCap is proven to mediate the relationship between AL and innovative work behavior ( $\mathrm{B}=0.071, \mathrm{SE}=0.036,95 \% \mathrm{CI}[0.009,0.150])$. Additional findings also show that $\mathrm{AL}$ and innovative work behavior have a significant positive relationship $(\mathrm{B}=$ $0.45, \mathrm{R} 2=0.044, \mathrm{~F}(1.113)=5.15, \mathrm{p}<0.05)$. AL is found to have a significant positive relationship with PsyCap $(\mathrm{B}=0.242, \mathrm{R} 2=0.200, \mathrm{~F}(1,113)=28,169, \mathrm{p}<0.01)$. Furthermore, it is found that PsyCap has a significant effect on innovative work behavior $(\mathrm{B}=0.355, \mathrm{R} 2=$ $0.086, \mathrm{~F}(1.113)=9.449, \mathrm{p}<0.05)$.

Table I. Correlation Matrix

\begin{tabular}{|c|c|c|c|c|c|c|c|c|c|c|}
\hline Variables & $\mathbf{M}$ & SD & 1 & 2 & 3 & 4 & 6 & 7 & 8 & 9 \\
\hline Sex & 1.504 & .502 & - & & & & & & & \\
\hline Age & 26.156 & 3.237 & -.044 & - & & & & & & \\
\hline Tenure & 24.565 & 25.682 & .034 & $.516 * *$ & - & & & & & \\
\hline Edu & 3.034 & .724 & $\begin{array}{l}- \\
.193 *\end{array}$ & $.345^{* *}$ & -.026 & - & & & & \\
\hline Type & 1.391 & .721 & -.065 & .019 & -.051 & .007 & - & & & \\
\hline PsyCap & 58.217 & 6.856 & .009 & .009 & .058 & .009 & -.003 & - & & \\
\hline AL & 69.600 & 12.638 & .097 & -.103 & .078 & $\begin{array}{l}- \\
.225^{*}\end{array}$ & -.014 & $.447 * *$ & - & \\
\hline IWB & 38.713 & 8.755 & .133 & .087 & .175 & .035 & -.075 & $.278^{* *} *$ & $.209 *$ & - \\
\hline
\end{tabular}

${ }^{a}$ Note. $\mathrm{N}=115$. Sex was dummy-coded (1=female, $2=$ male), Age in years, Tenure: Job Tenure (measured in months), Edu: Education was dummy-coded (1=high school, 2=Diploma, 3= Master's degree, 4=Bachelor's degree), Type: Organization types was dummy-coded (1= private, 2=government, $3=$ non-profit, $4=$ others), PsyCap: Psychological Capital, AL: Authentic Leadership, IWB: Innovative Work Behavior, *p < 0.05; ** $\mathrm{p}<$ 0.01 .

Table II. Hypotheses Testing using PROCESS Macro

\begin{tabular}{lllllll}
\hline Model & B & SE & 95\% CI & R2 & F & t \\
\hline 1 & $0.145^{*}$ & 0.064 & {$[0.018,0.271]$} & 0.044 & 5.150 & 2.269 \\
2 & $0.242^{* *}$ & 0.046 & {$[0.152,0.333]$} & 0.200 & 28.169 & 5.307 \\
3 & $0.294^{*}$ & 0.129 & {$[0.039,0.550]$} & 0.086 & 9.449 & 3.074 \\
4 & $0.071^{*}$ & 0.036 & {$[0.009,0.150]$} & & & \\
\hline
\end{tabular}

Note. Model 1: AL $\rightarrow$ Innov; Model 2: AL $\rightarrow$ PsyCap; Model 3: PsyCap $\rightarrow$ Innov; Model 4: AL $\rightarrow$ PsyCap $\rightarrow$ Innov, $* \mathrm{p}<0.05, * * \mathrm{p}<0.001$ 


\section{Discussion}

Based on the data analysis undertaken, the results broadly confirm the hypothesis. We found that the effect of AL on innovative work behavior is fully mediated by PsyCap. This finding fulfills a pre-existing research gap by providing a new perspective on how authentic leaders influence innovative work behavior. As found in previous studies, AL supports individuals toward positive achievement and resiliency, building trust and hope, both of which, in turn, help employees to propose innovative ideas without hesitation (Zhou, 2014; Rego, et.al., 2014). When individuals posit innovative work behavior, they will face an unstoppable trial-error ideas generation process which is highly related to work stress, and therefore their PsyCap will help an individual to successfully navigate it (Abbas, \& Raja, 2015; Ziyae, Mobaraki, \& Saeediyoun, 2105). This finding supports prior research which found that AL will impact upon employees personal PsyCap, thereby increasing idea generation and problem-solving. This will, in turn, promote idea realization (Ziyae, Mobaraki, \& Saeediyoun, 2105). Thus, AL needs to affect an individual's PsyCap to enhance the innovative behavior because an authentic leader has a stronger psychological appeal that will influence individual PsyCap as psychological resources enhancing the ability to perform innovative behavior (Schuckert, et al., 2018).

Meanwhile, AL and innovative work behavior are also found to exhibit a positive relationship. This finding supports previous studies (Zhou, 2014; Schuckert, et.al., 2018). It is also in line with a study by Černe et al. (2013) which found that employees who perceived their leaders as an authentic leader, will increase their effort toward doing innovative work within a group setting.

Moreover, we found that AL predicts PsyCap. This finding is in accordance with previous studies (Schuckert, et al., 2018; Munyaka, et.al., 2017; Wang, et.al., 2014; Wolley, Caza, \& Levy, 2011). The characteristics of AL provide moral internalization and transparent relationships and thus care for employees' welfare. In turn, this will help the employees, not only to understand the goals of the company itself, but also to understand what is expected of them in the workplace more clearly (Schuckert, et al., 2018). Following from the trust and appreciation imparted by authentic leaders, employees may build self-efficacy that proves helpful in idea realization (Schuckert, et al., 2018), produces novelty (Abbas, \& Raja, 2015), and emboldens them to take risky actions and show extraordinary effort to innovate (Zhou, 2014).

Finally, PsyCap has been found to predict innovative work behavior. Earlier findings posit that individuals who are high in PsyCap are better able to produce, and obtain support for, implementation of new ideas in their workplace (Abbas, \& Raja, 2015). PsyCap has been found to have a significant effect on innovative behavior because it is a form of positive psychological resource (Zhou, 2014). Individuals with PsyCap tend to have goal orientation because they have optimism and hope. Hence, employees will dare to face and resolve the problems encountered at work. PsyCap's dimensions can, individually and in concert, contribute to the necessary support required for innovative performance, e.g., confidence in one's abilities, optimistic future expectations, hopeful thinking, and resilient perseverance (Luthans, Youssef, \& Rawski, 2011). 


\section{Practical Implication}

These findings could form a basis for human resource practitioners to support individual psychological capital in order to enhance innovation in the workplace. The positivity of psychological capital in shaping innovative work behavior will be especially impactful in fourth industrial revolution technology, wherein innovation can greatly contribute to competitiveness and thus profitability. Hence, to affect their followers PsyCap, leaders must apply proper leadership styles as per this study findings vis-à-vis what constitutes AL. Some practical human resources that companies could arrange are as follows: (1) provide AL training for leaders in the organization; (2) set up a systematic mapping program that allocate leaders with higher AL to work teams that require PsyCap development the most; and (3) recruit employees with high PsyCap and provide training as needed in order to maintain and develop their PsyCap; and, lastly (4) conduct short-term training on positive work attitudes, career planning, increased creativity and problem-solving to maintain and improve PsyCap employees.

\section{Limitations}

Aside from its advantages in providing deeper understanding of antecedents of innovative work behavior, this study does have, however, limitations that need to be addressed. Firstly, the use of self-report questionnaires may lead to common method bias. This study uses a single source and self-report questionnaire that may lead to high social desirability bias (Podsakoff, 2003). We have undertaken some procedures to minimize this bias, by disguising the research title and its purpose, and never mentioned the research variables on the instrument. We also manipulated the items' order and sequence and made sure participants fully understood that their confidentiality is guaranteed.

Secondly, the study is a cross-sectional study and the sample may not represent the population as a whole. Future studies may conduct longitudinal research and should use a larger representative sample. Therefore, we cannot conclude the causal direction of the effects of the study variables, and we cannot generalize the result of the study to larger organizations. Moreover, the minimum job tenure is not specified in this study, because some employees may not be (as yet) familiar with their leader in such a short period of time. Hence, we recommend the setting of a minimum requirement of job tenure in gathering research participants. We assume that six months of job tenure is sufficient to assume that employees have interacted intensively with their direct supervisors. Lastly, we suggest exploration of the other variables which can influence innovative work behavior (e.g., creativity and organizational innovation climate).

\section{Conclusion}

Based on the data analysis undertaken, the results confirm the research statement that: "PsyCap fully mediates the relationship between AL and innovative work behavior." The direct relationship between AL and innovative work behavior weakens as PsyCap acts as a mediator. In addition, there is a positive relationship between AL and innovation, AL with PsyCap, and PsyCap with innovative work behavior among employees. 


\section{References}

Abbas, M. \& and Raja, R. (2015). Impact of psychological capital on innovative performance and job stress. Canadian Journal of Administrative Sciences/Revue Canadienne des Sciences de l'Administrationl 'Administration, 32(2), 128-138.

Abdolmaleki, J., Ashloublagh, M., Shahrabi, M., Ashlaghi, A., \& Safdari, S. (2013). A study on effects of leadership style on innovation: A case study from automaker industry. Management Science Letters, 3(7), 1977-1982.

Afsar, B., and \& Masood, M. (2018). Transformational leadership, creative self-efficacy, trust in supervisor, uncertainty avoidance, and innovative work behavior of nurses. The Journal of Applied Behavioral Science, 54(1), 36-61.

Agarwal, A., and \& Upasna, (initial). (2014). Linking justice, trust and innovative work behaviour to work engagement. Personnel Review, 43(1), 41-73.

Agbim, K. C. (2013). The impact of organizational structure and leadership styles on innovation. IOSR Journal of Business and Management (IOSR-JBM), 6(6 ), 56-63.

Ahmad, J. N. (2016). Intervention design gain sharing system to improve innovative work behavior and organization climate in ABC office (Master thesis). Universitas Indonesia, Depok.

Avolio, B. J., and \& Gardner, W. L. (2005). Authentic leadership development: Getting to the root of positive forms of leadership. The leadership quarterly, 16(3), 315-338.

Avolio, B. J., Walumbwa, F. O., \& Weber, T. J. (2009). Leadership: Current theories, research, and future directions. Annual Review of Psychology, 60, 421-449.

Baer, M. (2012). Putting creativity to work: The implementation of creative ideas in organizations. Academy of Management Journal, 55(5), 1102-1119.

Baer, Markus, and \& Frese, M. (2003). Innovation is not enough: Climates for initiative and psychological safety, process innovations, and firm performance. Journal of Organizational Behavior: The International Journal of Industrial, Occupational and Organizational Psychology and Behavior, 24(1), 45-68.

Banks, G. C., McCauley, K. D., Gardner, W. L., \& Guler, C. E. (2016). A meta-analytic review of authentic and transformational leadership: A test for redundancy. The Leadership Quarterly, 27(4), 634-652.

Černe, M., Jaklič, M., \& and Škerlavaj, M. (2013). Authentic leadership, creativity, and innovation: A multilevel perspective. Leadership, 9(1), 63--85.

De Jong, Jeroen, P. J., and\& Den Hartog, D. N. (2007). How leaders influence employees' innovative behaviour. European Journal of innovation management, 10(1), 41-64.

Edú-Valsania, S., Moriano, J. A., \& Molero, F. (2016). Authentic leadership and employee knowledge sharing behavior: Mediation of the innovation climate and workgroup identification. Leadership \& Organization Development Journal, 37(4), 487-506.

Elrehail, H., Emeagwali, O. L., Alsaad, A., \& Alzghoul, A. (2018). The impact of transformational and authentic leadership on innovation in higher education: the contingent role of knowledge sharing. Telematics and Informatics, 35(1), 55-67.

Fredrickson, B. L. (2004). The broaden-and-build theory of positive emotions. Philosophical Transactions of the Royal Society of London. Series B: Biological Sciences, 359(1449), 1367-1377.

Gonçalves, L. \& Brandão, F. (2017). The relation between leader's humility and team creativity: The mediating effect of psychological safety and psychological capital. International Journal of Organizational Analysis, 25(4), 687-702.

Harborne, P. \& Axel, J. (2003). Creating a project climate for successful product innovation. European Journal of innovation management, 6(2), 118-132.

Hayes, A. F. (2013). Introduction to Mediation, Moderation, and Conditional Process Analysis: A RegressionBased Approach. New York, NY: The Guilford Press.

Hsu, M. L. A. \& Chen, F. H. (2017). The cross-level mediating effect of psychological capital on the organizational innovation climate-employee innovative behavior relationship. The Journal of Creative Behavior, 51(2), 128-139.

Ilies, R., Morgeson, F. P., \& Nahrgang, J. D. (2005). Authentic leadership and eudaemonic well-being: Understanding leader-follower outcomes. The Leadership Quarterly, 16(.3), 373-394. 
Janssen, O. (2000). Job demands, perceptions of effort-reward fairness and innovative work behaviour. Journal of Occupational and organizational psychology, 73(3), 287-302.

Janssen, O., de Vliert, E. V., \& West, M. (2004). The bright and dark sides of individual and group innovation: A special issue introduction. Journal of Organizational Behavior, 25(2), 129-145.

Luthans, F., Avolio, B. J., Avey, J. B., \& Norman, S. M. (2007). Positive psychological capital: Measurement and relationship with performance and satisfaction. Personnel psychology, 60(3), 541-572.

Luthans, F., Youssef, C. M., \& Rawski, S. L. (2011). A tale of two paradigms: The impact of psychological capital and reinforcing feedback on problem solving and innovation. Journal of Organizational Behavior Management, 31(4), 333-350.

Maher, A., Mahmoud, H. S., \& El Hefny, S. (2017). Authentic Leadership and Psychological Capital: The Impact on Egyptian Employees' Work Well Being. Electronic Journal of Knowledge Management, 15(3).

Meliala, R. S. (2014). The influence of the authentic leadership and the organizational culture on employee value proposition case study in putera sampoerna foundation (Master thesis). Universitas Indonesia, Depok.

Müceldili, B., Turan, H., \& Erdil, O. (2013). The influence of authentic leadership on creativity and innovativeness. Procedia-Social and Behavioral Sciences, 99, 673-681.

Munyaka, S. A., Boshoff, A. B., Pietersen, J., \& Snelgar, R. (2017). The relationships between authentic leadership, psychological capital, psychological climate, team commitment and intention to quit. $S A$ Journal of Industrial Psychology, 43(1), 1-11.

Neider, L. L., \& Schriesheim, C. A. (2011). The authentic leadership inventory (ALI): Development and empirical tests. The leadership quarterly, 22(6), 1146-1164.

Podsakoff, P. M., MacKenzie, S. B., Lee, J. Y., \& Podsakoff, N. P. (2003). Common method biases in behavioral research: A critical review of the literature and recommended remedies. Journal of applied psychology, 88(5), 879-903.

Rego, A., Sousa, F., Marques, C., \& e Cunha, M. P. (2012). Authentic leadership promoting employees' psychological capital and creativity. Journal of Business Research, 65(3), 429-437.

Rego, A., Sousa, F., Marques, C., \& e Cunha, M. P. (2014). Hope and positive affect mediating the authentic leadership and creativity relationship. Journal of Business Research, 67(2), 200-210.

Rulevy, D. F. \& Parahyanti, E. (2018). Hubungan Psychological Capital Dan Perilaku Kerja Inovatif Di Industri Kreatif: Studi Pada Karyawan Perusahaan Xyz. Journal Psikogenesis. 4(1), 99-113.

Saeed, B. B., Afsar, B., Cheema, S., \& Javed, F. (2019). Leader-member exchange and innovative work behavior: The role of creative process engagement, core self-evaluation, and domain knowledge. European Journal of Innovation Management, 22(1), 105-124.

Sameer, Y. M. (2018). Innovative behavior and psychological capital: Does positivity make any difference? Journal of Economics \& Management, 32, 75-101.

Schuckert, M., Kim, T. T., Paek, S., \& Lee, G. (2018). Motivate to innovate: How authentic and transformational leaders influence employees' psychological capital and service innovation behavior. International Journal of Contemporary Hospitality Management, 30(2), 776-796.

Scott, S. G., \& Bruce, R. A. (1994). Determinants of innovative behavior: A path model of individual innovation in the workplace. Academy of management journal, 37(3), 580-607.Stamler, Philip, W. (2007). Closing the innovation gap for business sustainability (Doctoral dissertation). Walden University, Minnesota.

Waite, A. M. (2014). Leadership's influence on innovation and sustainability: A review of the literature and implications for HRD. European Journal of Training and Development, 38(1/2), 15-39.

Walumbwa, F. O., Avolio, B. J., Gardner, W. L., Wernsing, T. S., \& Peterson, S. J. (2008). Authentic leadership: Development and validation of a theory-based measure. Journal of Management, 34(1), 89-126.

Wang, H., Sui, Y., Luthans, F., Wang, D., \& Wu, Y. (2014). Impact of authentic leadership on performance: Role of followers' positive psychological capital and relational processes. Journal of Organizational Behavior, 35(1), 5-21.

Woolley, L., Caza, A., \& Levy, L. (2011). Authentic leadership and follower development: Psychological capital, positive work climate, and gender. Journal of Leadership \& Organizational Studies. 18(.4): 438-448.

World Economic Forum. (2018). The Next Economic Growth Engine Scaling Fourth Industrial Revolution Technologies in Production. from 
http://www3.weforum.org/docs/WEF_Technology_and_Innovation_The_Next_Economic_Growth_En gine.pdf

Yoshida, D. T., Sendjaya, S., Hirst, G., \& Cooper, B. (2014). Does servant leadership foster creativity and innovation? A multi-level mediation study of identification and prototypicality. Journal of Business Research, 67(7), 1395-1404.

Youndt, M. A., Snell, S. A., Dean Jr, J. W., \& Lepak, D. P. (1996). Human resource management, manufacturing strategy, and firm performance. Academy of management Journal, 39(4), 836-866.

Zhou, J., Ma, Y., Cheng, W., \& Xia, B. (2014). Mediating role of employee emotions in the relationship between authentic leadership and employee innovation. Social Behavior and Personality: an international journal, 42(8), 1267-1278.

Ziyae, B., Mobaraki, M. H., \& Saeediyoun, M. (2015). The effect of psychological capital on innovation in information technology. Journal of Global Entrepreneurship Research, 5(1), 8. 